\title{
UPDATES IN ANTIBIOTIC THERAPY OF BILIARY TRACT INFECTIONS
}

\author{
Cristian Balahura ${ }^{1,2}$, Petre Iacob Calistru ${ }^{1,3}$, Gabriel Constantinescu ${ }^{1,2}$ \\ I" Carol Davila" University of Medicine and Pharmacy, Bucharest \\ 2"Floreasca" Emergency Hospital, Bucharest \\ 3 "Dr. Victor Babes" Infectious and Tropical Diseases Hospital, Bucharest
}

\begin{abstract}
Introduction. The management of biliary tract infections involves systemic antibiotherapy and a biliary drainage procedure. Current guidelines provide recommendations for empirical antimicrobial therapy in cholangitis but development of multi-drug resistant organisms can make many of these antibiotics ineffective. This study aimed to analyze the microbiology of bile and the susceptibility profiles of organisms identified in patients with extrahepatic cholestatis, with or without a previously placed biliary stent.

Materials and methods. We conducted a prospective study including 136 patients with biliary obstruction who were endoscopically drained between June 2014 and March 2015 in Emergency Hospital "Floreasca", Bucharest. One hundred and four of these patients had no biliary stent in situ (group 1). Thirty-two procedures were performed in patients with at least one biliary stent in place (group 2). Microbiological examination of bile aspirates was performed and antibiotic susceptibilities were determined for the isolated bacteria.

Results. One hundred eighteen of 136 analyzed cultures were positive ( $81 \%$ in group 1 vs. $100 \%$ in group 2 ; $\mathrm{p}<0.05$ ). In both groups, the most frequent pathogens were Escherichia coli, Klebsiella spp. and Proteus spp. The most effective antimicrobial agents against Gram-negative bacteria in group 1 and group 2 were imipenem, cefoperazone/sulbactam and piperacillin/tazobactam. Susceptibilities to ceftazidime, cefotaxime, cefepime and fluoroquinolones were significantly lower in group 2.

Conclusion. This survey shows that Gram-negative bacteria are the predominant bile pathogens found in patients with cholestatis. Cefoperazone/sulbactam, piperacillin/tazobactam or imipenem can be recommended in biliary infections. Cephalosporins and fluroquinolones should not be used as empirical therapy if a biliary stent is in place.
\end{abstract}

Keywords: biliary infection, biliary stent, antibiotics, antibiotic susceptibility

\section{ACKNOWLEDGEMENT}

This paper is supported by the Sectoral Operational Programme Human Resources Development (SOPHRD), financed from the European Social Fund and by the Romanian Government under the contract number POSDRU/159/1.5/S/137390.

\section{INTRODUCTION}

Biliary tract infection is a systemic disease resulting from a combination of obstruction, bacterial proliferation and inflamation in the biliary tree. The disease is most commonly associated with gallstone disease, benign or malign biliary strictures but may occur as a complication after biliary stenting.
The management of acute cholangitis is aimed at controlling biliary infection and obtaining biliary decompression and involves systemic antibiotics and biliary drainage procedures (1). Endoscopic retrograde cholangiopancreatography (ERCP) is the procedure of choice for restoring the bile flow (source control) (2). Current management guidelines for biliary infections (Tokio Guidelines 2013 
- TG13) provide useful criteria for establishing the severity of disease (Table 1).

TABLE 1. TG13 severity criteria for acute cholangitis (3)

\begin{tabular}{|c|c|}
\hline \multicolumn{2}{|c|}{$\begin{array}{l}\text { Grade III ( Severe) acute cholangitis: associated onset of } \\
\text { dysfunction in at least one of any of the following organs/ } \\
\text { systems: }\end{array}$} \\
\hline $\begin{array}{l}\text { Cardiovascular } \\
\text { dysfunction }\end{array}$ & $\begin{array}{l}\text { Hypotension requiring } \\
\text { dopamine } \geq 5 \mu \mathrm{g} / \mathrm{kg} \text { per min, } \\
\text { or any dose of norepinephrine }\end{array}$ \\
\hline - Neurological dysfunction & Disturbance of consciousness \\
\hline - Respiratory dysfunction & $\mathrm{PaO}_{2} / \mathrm{FiO}_{2}$, ratio $<300$ \\
\hline - Renal dysfunction & $\begin{array}{l}\text { Oliguria, serum } \\
\text { creatinine }>2.0 \mathrm{mg} / \mathrm{dl}\end{array}$ \\
\hline - Hepatic dysfunction & INR $>1.5$ \\
\hline $\begin{array}{l}\text { - Hematological } \\
\text { dysfunction }\end{array}$ & Platelet count $<100,000 / \mathrm{mm}^{3}$ \\
\hline \multicolumn{2}{|c|}{$\begin{array}{l}\text { Grade II (moderate) acute cholangitis: associated with any } \\
\text { two of the following conditions: }\end{array}$} \\
\hline - Abnormal WBC count & $>12,000 / \mathrm{mm}^{3},<4,000 / \mathrm{mm}^{3}$ \\
\hline - High fever & $\geq 39^{\circ} \mathrm{C}$ \\
\hline - Age & $\geq 75$ years old \\
\hline - Hyperbilirubinemia & total bilirubin $>5 \mathrm{mg} / \mathrm{dL}$ \\
\hline - Hypoalbuminemia & $<$ STD $\times 0.7$ \\
\hline \multicolumn{2}{|c|}{$\begin{array}{l}\text { Grade I (mild) acute cholangitis: does not meet the criteria of } \\
\text { "Grade III (severe)" or "Grade II (moderate)“ acute cholangitis } \\
\text { at initial diagnosis }\end{array}$} \\
\hline \multicolumn{2}{|c|}{$\begin{array}{l}\text { STD - lower limit of normal value } \\
\text { TG13 - Tokio Guidelines } 2013\end{array}$} \\
\hline
\end{tabular}

Empiric antibiotic therapy is mandatory in all patients with acute biliary infection, before the spe- cific bacterial etiology is confirmed. It should be initiated as soon as the diagnosis is suspected, before the performance of any decompression procedure but after drawing blood cultures (2). When the results of cultures and susceptibility studies are available the antibiotics should be accordingly changed (de-escalation) (4). Still, positive rates of blood cultures are reported to be as low as $21-71 \%$ in these patients while bile cultures have higher rates of positive results ranging from 59 to $93 \%$. Current guidelines recommend that bile be sent for culture in all cases of suspected cholangitis (5).

TG13 provide recommendations for empiric antimicrobial therapy in cholangitis. The initial choice of an antibacterial agent should be based on local microbial epidemiology, severity of disease and patient-specific factors, including prior contact with the healthcare system. These recommendations are summarized in Table 2.

As emphasized in TG13, rapid development of multi-drug resistant organisms should be considered when choosing empiric antimicrobial therapy. Pathogens profile may not be the same in different areas so local data knowledge is necessary for establishing adequate empiric antibacterial regimens.

In Romania recent epidemiologic studies on the microbiology of biliary infections are scarce. The aim of our study was to determine the microbio-

TABLE 2. Antibiotic recommendations for acute biliary infections (5)

\begin{tabular}{|c|c|c|c|}
\hline \multirow[t]{2}{*}{ Antibiotic agent } & \multicolumn{3}{|c|}{ Severity } \\
\hline & $\begin{array}{l}\text { Mild cholangitis } \\
\text { (community-acquired) }\end{array}$ & $\begin{array}{l}\text { Moderate cholangitis } \\
\text { (community-acquired) }\end{array}$ & $\begin{array}{l}\text { Severe cholangitis (community-acquired) } \\
\text { Healthcare-associated cholangitis }\end{array}$ \\
\hline Penicillin-based therapy & $\begin{array}{l}\text { Ampicillin/sulbactam is not } \\
\text { recommended without an } \\
\text { aminoglycoside }\end{array}$ & Piperacillin/tazobactam & Piperacillin/tazobactam \\
\hline \multirow[t]{2}{*}{ Cephalosporin- based therapy } & $\begin{array}{l}\text { Cefazolin, } \\
\text { or cefotiam, } \\
\text { or cefuroxime, } \\
\text { or ceftriaxone, } \\
\text { or cefotaxime } \\
\pm \text { metronidazole } \\
\end{array}$ & $\begin{array}{l}\text { Ceftriaxone, } \\
\text { or cefotaxime } \\
\text { or cefepime } \\
\text { or cefozopran } \\
\text { or ceftazidime } \\
\pm \text { metronidazole }\end{array}$ & $\begin{array}{l}\text { Cefepime } \\
\text { or ceftazidime } \\
\text { or cefozopran } \\
\pm \text { metronidazole }\end{array}$ \\
\hline & $\begin{array}{l}\text { Cefmetazole, cefoxitin } \\
\text { flomoxef, cefoperazone/ } \\
\text { sulbactam }\end{array}$ & Cefoperazone/sulbactam & \\
\hline Carbapenem-based therapy & Ertapenem & Ertapenem & $\begin{array}{l}\text { Imipenem/cilastatin, } \\
\text { meropenem, } \\
\text { doripenem, } \\
\text { ertapenem }\end{array}$ \\
\hline Monobactam-based therapy & & & Aztreonam \pm metronidazole \\
\hline \multirow[t]{2}{*}{$\begin{array}{l}\text { Fluoroquinolone-based therapy } \\
\text { ( } \beta \text {-lactam allergies) }\end{array}$} & $\begin{array}{l}\text { Ciprofloxacin, } \\
\text { or levofloxacin, } \\
\text { or pazufloxacin } \\
\pm \text { metronidazole } \\
\text { Moxifloxacin }\end{array}$ & $\begin{array}{l}\text { Ciprofloxacin, } \\
\text { or levofloxacin, } \\
\text { or pazufloxacin } \\
\pm \text { metronidazole } \\
\text { Moxifloxacin }\end{array}$ & - \\
\hline & & & $\begin{array}{l}\text { Vancomycin } \\
\text { (Linezolid/ Daptomycin) }\end{array}$ \\
\hline
\end{tabular}


logical characteristics of bile and antimicrobial susceptibilities in patients with extrahepatic cholestatis, with or without a biliary stent, who underwent ERCP for biliary decompression.

\section{MATERIALS AND METHODS}

\section{Study population}

We included in a prospective observational study 136 patients (57\% male, mean age $63 \pm 17$ years) refferred for therapeutic ERCP to the Department of Digestive Endoscopy, "Floreasca" Clinical Emergency Hospital between June 2014 and March 2015 with a diagnosis of extrahepatic cholestatis. The inclusion criteria were as follows: elevated cholestatis parameters (GGT $>55 \mathrm{U} / 1$ and ALP $>120 \mathrm{U} / \mathrm{l}$ ) and/or biliary dilation on imaging studies. The exclusion criteria were: hemodynamic instability, incomplete laboratory or imaging data or the absence of written informed consent before the procedure.

There were two groups of patients: those without biliary stents already inserted (group 1) and those with at least one stent in situ (group 2). A number of 104 procedures were performed in patients from group 1 and 32 procedures in patients from group 2 . The most common underlying biliary disease are shown in Table 3. Choledocholithiasis was statistically more frequent in group 1 $(p<0.0001)$ but stenoses were more likely found in group $2(\mathrm{p}<0,05)$.

TABLE 3. Main indications for ERCP in the study population

\begin{tabular}{|l|c|c|}
\hline Diagnosis & $\begin{array}{c}\text { Group 1 } \\
\text { (no stent) }\end{array}$ & $\begin{array}{c}\text { Group 2 } \\
\text { (+ stent) }\end{array}$ \\
\hline Choledocholithiasis & $79(77 \%)$ & $2(6 \%)$ \\
\hline $\begin{array}{l}\text { Distal malignant bile duct } \\
\text { obstruction }\end{array}$ & $13(12 \%)$ & $12(38 \%)$ \\
\hline $\begin{array}{l}\text { Proximal malignant bile } \\
\text { duct obstruction }\end{array}$ & $5(5 \%)$ & $8(25 \%)$ \\
\hline Benign biliary strictures & $7(6 \%)$ & $8(25 \%)$ \\
\hline Miscellaneous & 0 & $2(6 \%)$ \\
\hline
\end{tabular}

\section{Data collection}

Bile samples were obtained during ERCP. All endoscopes and accessories were disinfected following the recommendations of specific guideliness (6). Contamination was excluded by regular smear tests. Bile was aspirated through sterile catheters introduced directly into the bile duct during the endoscopic procedures. The specimens were transported in sterile tubes to the Microbiology laboratory where they were examined for aerobic and anaerobic pathogens. Microorganisms were cultured according to standard protocols. Identification of cultivable germs was performed using Vitek automated system (bio-Merieux). Antimicrobial susceptibility testing of bacterial isolates was assessed according to the Clinical and Laboratory Standards Institute (CLSI) Guidelines, using disk diffusion tests on Mueller-Hinton agar plates (Becton Dickinson).

\section{Statistical analysis}

Data from the two groups were compared using the Chi-Square tests or Fisher's exact test. All p values were based on two-tailed tests. A p-value $<0.05$ was considered as statistically significant. SPSS for Windows was used for analyses (SPSS 16.0, INC., Chicago, III).

\section{RESULTS}

Cultures were positive in 118 of $136(86 \%)$ bile specimens. Patients with a stent in place had more frequently bacterobilia: group 1, 85/104 (81\%), versus group 2, 32/32 (100\%) ( $<<0.05)$. Gramnegative bacteria were isolated in $80 \%$ of cases, Gram-positive bacteria in $18 \%$ and anerobes in 5\%. Monobacterial cultures were recorded in $59 \%$ of cases while $27 \%$ were polybacterial. Patients with a previously placed biliary stent had more frequently polymicrobial infections ( $40 \%$ vs. $22 \%$; p < 0.05 ). The most frequently encountered organisms were Gram-negative bacteria, including Escherichia coli (49\%), Klebsiella spp.(10\%) and Proteus spp. $(9 \%)$. E.coli was more likely to be found in group 2 ( $84 \%$ vs. $46 \% ; p=0.0005)$. Among Gram-positive microorganisms, Enterococci were most frequently identified. The frequency of other bacteria was similar in both groups. The frequency of different organisms in positive bile cultures is presented in Table 4.

The most effective antimicrobial agents against Gram-negative bacteria were imipenem, cefoperazone/sulbactam and piperacilline/tazobactam (susceptibility $89.6 \%, 83.2 \%, 82.3 \%$, respectively). Efficacy of imipenem, cefoperazone/sulbactam, piperacillin/tazobactam, cefuroxime, ceftriaxone was not statistically different in group 1 and group 2 .

Susceptibilities to other antibiotics were significantly different in group 1 and group 2: ceftazidime $(67 \%$ vs. $35 \% ; p=0.001)$, cefotaxime $(58 \%$ vs. $35 \% ; \mathrm{p}=0.03)$, cefepime $(68 \%$ vs. $40 \% ; \mathrm{p}=0.003)$ and fluoroquinolones ( $69 \%$ vs. $27 \% ; p<0.001)$. 
TABLE 4. Bacteriology of positive bile cultures in patients with or without biliary stents $n(\%)$

\begin{tabular}{|l|c|c|}
\hline Bacteria & $\begin{array}{c}\text { Group 1 } \\
\text { (no stent) }\end{array}$ & $\begin{array}{c}\text { Group 2 } \\
\text { (+ stent) }\end{array}$ \\
\hline E.coli & $40(46 \%)$ & $27(84 \%)$ \\
\hline Enterococcus spp. & $17(19 \%)$ & $6(19 \%)$ \\
\hline Klebsiella spp. & $12(13 \%)$ & $2(6 \%)$ \\
\hline Pseudomonas aeruginosa & $10(11 \%)$ & $2(6 \%)$ \\
\hline Proteus spp. & $7(8 \%)$ & $6(19 \%)$ \\
\hline Citrobacter spp. & $7(8 \%)$ & $1(3 \%)$ \\
\hline Enterobacter spp. & $6(7 \%)$ & $1(3 \%)$ \\
\hline Acinetobacter spp. & $4(4 \%)$ & $1(3 \%)$ \\
\hline Providencia spp. & $3(3 \%)$ & $0(0 \%)$ \\
\hline Serratia marcescens & $2(2 \%)$ & $0(0 \%)$ \\
\hline Morganella spp. & $2(2 \%)$ & $1(3 \%)$ \\
\hline Stafilococccus aureus & $2(2 \%)$ & $0(0 \%)$ \\
\hline $\begin{array}{l}\text { Stenotrophomonas } \\
\text { maltophilia }\end{array}$ & $1(1 \%)$ & $0(0 \%)$ \\
\hline Anaerobes & $6(7 \%)$ & $2(6 \%)$ \\
\hline
\end{tabular}

The antimicrobial susceptibility of the most frequently isolated organisms from our study population is shown in Figure 1.

Gram-positive pathogens were $92 \%$ susceptible to vancomycin but only $59 \%$ to fluoroquinolones. Resistance to this antibiotics was not statistically different in group 1 and group 2.

\section{DISCUSSION}

Our survey confirms Gram-negative bacteria (Enterobacteriaceae) to be the predominant pathogens in bile culture isolates from patients with cholestatis, regardless of whether a biliary stent is in place or not. E.coli was the most frequent germ isolated from both groups. Our results are similar to those reported in other studies (5). There was a low frequency of anaerobic bacteria, which were isolated in $6 \%$ of cultures $(8 \%$, group $1 ; 3 \%$, group 2 ; $\mathrm{p}=0.5813)$. This corresponds to the literature data reporting anaerobic pathogens in $<10 \%$ of positive cultures (7).

Different pathogen profiles were found in patients with previous biliary interventions. Polymicrobial bile cultures were more frequently encountered in patients with stents in situ ( $40 \%$ vs. $22 \%$; $\mathrm{p}<0,05)$. Similar findings were reported by previous studies (8).

Ampicillin/sulbactam is a frequently used agent for intra-abdominal infections. Still, the activity of this agent against Gram-negative bacteria has dramatically fallen. In our study the sensitivity to ampicillin/sulbactam of Gram-negative bacteria isolated from group 1 and group 2 was $52 \%$ and $14 \%$, respectively. Therefore this agent should not be used alone in biliary infections. Fluoroquinolones were only effective in $58 \%$ of cases $(69 \%$, group 1 ; $27 \%$, group $2 ; \mathrm{p}<0.001)$. This antimicrobial agents may be efficient in patients without biliary stents but will not effectively cover bacteria in stent-associated cholangitis.

Imipenem was associated with the smallest resistance rate of bacteria (10\%). Cefoperazone/sulbactam and piperacillin/tazobactam also had good efficacy, of $83.2 \%$ and $82.3 \%$ respectively. These characteristics did not differ statistically in group 1 and group 2.

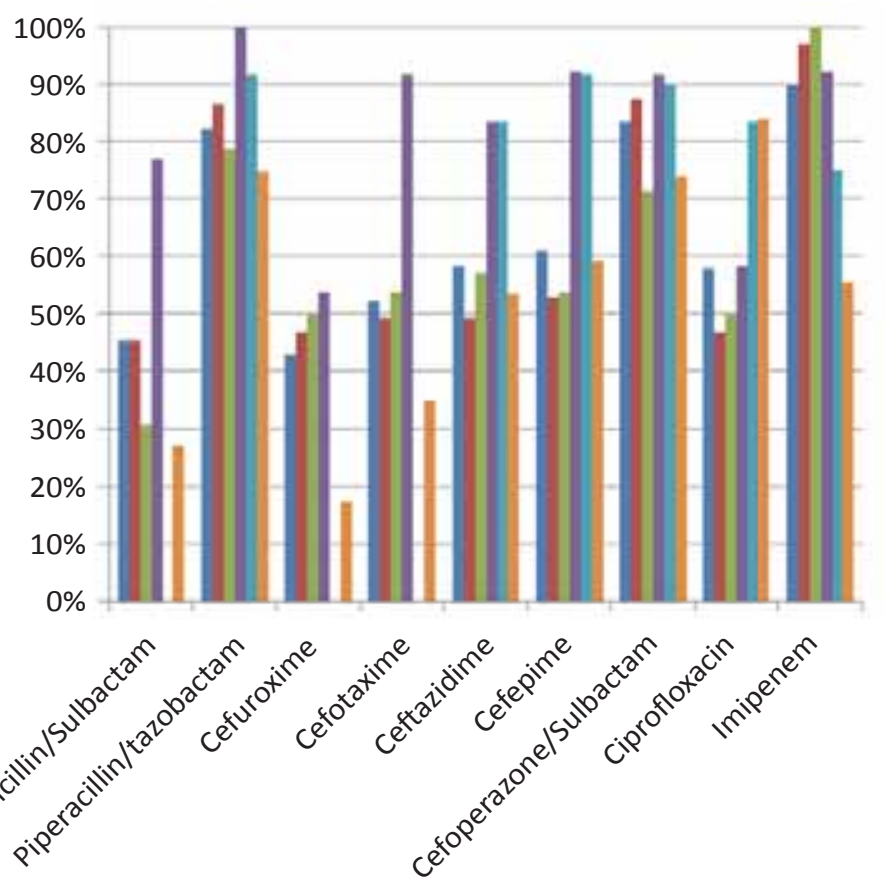

- All Gram-negative

E.coli

- Klebsiella spp.

- Proteus spp.

- Pseudomonas aeruginosa

n Other Gram-negative

FIGURE 1. The susceptibility of Gram-negative bacteria to the most effective antibiotics 
Although currently recommended by TG13 guidelines, the use of ceftazidime, cefotaxime and cefepime was associated in our survey with high levels of bacterial resistance. Therefore their empirical use should be very carefully considered, especially if a biliary stent is in place.

Our study provides information on the in vitro antibiotic susceptibility of bacteria involved in biliary infections. Still, these data do not warrant clinical effectiveness of a certain antibiotic therapy. This can be a limitation of this study. When approaching a patient, additional clinical features need to be balanced with microbiological data for best management strategy.

\section{CONCLUSIONS}

Gram-negative bacteria are predominantly isolated in bile cultures from patients with biliary tract infections, regardless of whether a biliary stent is in place or not. TG13 provide recommendations for empirical antimicrobial therapy of cholangitis but microbiological characteristics of pathogens may differ from center to center so local data knowledge is necessary for establishing adequate antibacterial regimens.

According to this survey, first-line therapy in cholangitis should include cefoperazone/sulbactam or piperacillin/tazobactam. Cephalosporins and fluoroquinolones should not be used alone for empirical therapy in patients with cholangitis and previously placed biliary stents. Imipenem, the most effective drug against Gram-negative bacteria, should be considered as an alternative, when other therapies fail. Empirical treatment with vancomycin can be considered if Enterococcus is of concern, especially in severe cholangitis or healthcareassociated acute biliary infections. This study offers evidence-based data for establishing effective empirical antimicrobial treatment of biliary infections.

\section{REFERENCES}

1. Salvador V.B.D., Lozada M.C.H., Consunji R.J. Microbiology and antibiotic susceptibility of organisms in bile cultures from patients with and without cholangitis at an Asian academic medical center. Surg Infect (Larchmt). 2011; 12(2):105-11.

2. Takada T., Strasberg S.M., Solomkin J.S., et al. TG13: Updated Tokyo Guidelines for the management of acute cholangitis and cholecystitis. J Hepatobiliary Pancreat Sci. 2013; 20(1):1-7.

3. Kiriyama S., Takada T., Strasberg S.M., et al. TG13 guidelines for diagnosis and severity grading of acute cholangitis (with videos). J Hepatobiliary Pancreat Sci. 2013; 20(1):24-34.

4. Dellinger R.P., Levy M.M., Rhodes A., et al. Surviving Sepsis Campaign: international guidelines for management of severe sepsis and septic shock, 2012. Intensive Care Med. 2013; 39(2):165-228.

5. Gomi H., Solomkin J.S., Takada T., et al. TG13 antimicrobial therapy for acute cholangitis and cholecystitis. J Hepatobiliary Pancreat Sci. 2013; 20(1):60-70.

6. Hookey L., Armstrong D., Enns R., et al. Summary of guidelines for infection prevention and control for flexible gastrointestinal endoscopy. Can J Gastroenterol. 2013; 27(6):347.

7. Csendes A., Mitru N., Maluenda F., et al. Counts of bacteria and pyocites of choledochal bile in controls and in patients with gallstones or common bile duct stones with or without acute cholangitis. Hepatogastroenterology. 1995; 43(10):800-6.

8. Rerknimitr R., Fogel E.L., Kalayci C., et al. Microbiology of bile in patients with cholangitis or cholestasis with and without plastic biliary endoprosthesis. Gastrointest Endosc. 2002; 56(6):885-9. 